\title{
POLÍTICAS DE FORMAÇÃO DE PROFESSORES: O QUE DETERMINA A LEGISLAÇÃO DE CRIAÇÃO DE SISTEMAS MUNICIPAIS DE ENSINO NO ESTADO DO PIAUÍ
}

\author{
TRAINING POLICIES OF TEACHERS: WHAT DETERMINES THE LEGISLATION OF CREATION OF MUNICIPAL \\ EDUCATION SYSTEMS IN THE STATE OF PIAUÍ
}

\author{
UN ENSAYO BIOGRÁFICO: MEMORIAS DEL PROFESOR SVEN ROBERT SCHULZE
}

\author{
RIBEIRO, Raimunda Maria da Cunha ${ }^{1}$
}

\section{RESUMO}

Este estudo tem como objetivo analisar o que determinam as Leis de criação dos sistemas municipais de ensino do Piauí sobre políticas de formação de professores. A metodologia foi qualitativa e quantitativa, e a técnica de coleta de dados foi a análise documental. No conjunto das Leis analisamos o dispositivo sobre formação de professores e suas particularidades, totalizando 86 documentos, em um universo de 90, pois, não tivemos acesso a 4 Leis. O conjunto da legislação analisada traz as seguintes orientações: programas de atualização e aperfeiçoamento; valorização assegurada no Plano de Carreira; formação contínua e sistemática; aperfeiçoamento com licenciamento. As diretrizes para esta formação tendem a levar em conta, principalmente, as necessidades imediatas dos municípios; os cursos não vão muito além de atualização e aperfeiçoamento do professor e a formação de competências. Os exemplos pontuais citados no texto destacam a presença do pacto federativo e o regime de colaboração entre os entes federados, assim como a participação das instituições de ensino superior no processo de formação de professores (UESPI, UFPI, IFPI, UAB/PI), embora sem descartarmos as influências dos campos político e econômico. Palavras-chave: Políticas de formação de professores. Sistemas municipais de ensino. Piauí

\section{ABSTRACT}

This study aims to analyze what determines the Laws of creation of the municipal systems of education of Piauí on teacher education policies. The methodology was qualitative and quantitative, and the technique of data collection was the documentary analysis. In the set of Laws we analyze the device on teacher training and its peculiarities, totaling 86 documents, in a universe of 90, because, we did not have access to 4 Laws. The set of legislation analyzed has the following guidelines: updating and improvement programs; valuation assured in the Career Plan; continuous and systematic training; licensing improvement. The guidelines for this training tend to take into account, mainly, the immediate needs of municipalities; the courses do not go beyond updating and improving the teacher and the training of skills. The specific examples cited in the text highlight the presence of the federative pact and the collaboration between federated entities, as well as the participation of higher education institutions in the teacher training process (UESPI, UFPI, IFPI, UAB/PI). without discarding the influences of the political and economic fields.

Keywords: Teacher education policies. Municipal education systems. Piauí.

\section{RESUMEN}

Este estudio tiene como objetivo analizar lo que determinan las Leyes de creación de los sistemas municipales de enseñanza de Piauí sobre políticas de formación de profesores. La metodología fue cualitativa y cuantitativa, y la técnica de recolección de datos fue el análisis documental. En el conjunto de las Leyes analizamos el dispositivo sobre formación de profesores y sus particularidades, totalizando 86 documentos, en un universo de 90, pues, no tuvimos acceso a 4 Leyes. El conjunto de la legislación analizada trae las siguientes orientaciones: programas de actualización y perfeccionamiento; valorización asegurada en el Plan de Carrera; formación continua y sistemática; perfeccionamiento con licencia. Las directrices para esta formación tienden a tener en cuenta, principalmente, las necesidades inmediatas de los municipios; los cursos no van mucho más allá de la actualización y perfeccionamiento del profesor y la formación de competencias. Los ejemplos puntuales citados en el texto destacan la presencia del pacto federativo y el régimen de colaboración entre los entes federados, así como la participación de

\footnotetext{
1 Universidade Estadual do Piauí - UEP - Teresina - Piauí - Brasil
} 
las instituciones de enseñanza superior en el proceso de formación de profesores (UESPI, UFPI, IFPI, UAB / PI), aunque sin descartar las influencias de los campos político y económico.

Palabras clave: Políticas de formación de professores. Sistemas municipales de enseñanza. Piauí

\section{INTRODUÇÃO}

As transformações econômicas, ideológicas e políticas, imperativas do mundo atual, têm impactado em todos os setores da sociedade, e como não poderia ser diferente, o campo da educação, notadamente, não tem ficado imune. Em consequência, as políticas de gestão têm sido delineadas para dar conta dos desafios frente a essas transformações e, nesse cenário, têm sido resultantes das lógicas que regulam o funcionamento da sociedade, em específico, a lógica do capitalismo. Neste campo estão as políticas de formação de professores, fortemente influenciadas por questões econômicas, culturais e sociais, sendo, em alta medida, direcionadas para a obtenção de resultados.

Este estudo tem como objetivo analisar o que determinam as Leis de criação dos sistemas municipais de ensino no Estado do Piauí sobre políticas de formação de professores. A metodologia utilizada pauta-se pelos princípios da pesquisa qualitativa e quantitativa, adotando a análise documental como técnica de coleta de dados. O objeto analisado foi o conjunto das Leis referentes à criação dos sistemas municipais de ensino no estado do Piauí. Foram analisadas 86 Leis, já que não tivemos acesso a 4 Leis de um total de 90 . O Piauí tem 224 municípios, destes, 90 têm sistema próprio de ensino e 134 têm sistema integrado à Secretaria de Estado de Educação e Cultura (Seduc-PI). Por uma questão de organização didática, a análise ocorreu por mesorregião - Norte Piauiense, Centro Norte Piauiense, Sudeste Piauiense e Sudoeste Piauiense - divisão definida pelo IBGE.

A finalidade da utilização das duas abordagens de pesquisa (qualitativa e quantitativa) foi demonstrar os resultados de forma a prevalecer o equilíbrio entre a objetividade dos dados estatísticos apresentados em gráficos e tabelas e a subjetividade apontada para os conteúdos analisados na legislação. A análise do conteúdo, cuja categoria foi formação de professores, foi feita com base nos princípios orientados por Bardin (2010).

Elegemos como fundamentais nessa análise, os seguintes pontos: políticas sociais e educacionais no Estado capitalista; políticas e gestão de sistemas municipais do ensino público; políticas de formação de professores. Para introduzir os argumentos sobre estas temáticas, adotamos como aporte teórico os escritos de: Faleiros (2009); Paulo Netto (1992); Oliveira; Duarte (2005); Silva (2006); Frigotto (1996); Scheibe (2010); Kuenzer (1999); Alcarão (2003); Gatti (2010); Sacrsitán (1999); Pimenta (1995; 1999), dentre outros.

\section{DISCUTINDO POLÍTICAS DE FORMAÇÃO DE PROFESSORES}

Começamos nossa discussão na tentativa de compreender o significado e o sentido das políticas sociais, consideradas, em linhas gerais, como o conjunto de todas as políticas públicas, presentes nas ações do Estado, que tenta se mostrar como o representante da unidade política do "povo-nação" 
(SILVA, 2003, p. 21 - grifos do autor). As políticas sociais delineadas pelo Estado capitalista representam um resultado da relação e do complexo desenvolvimento das forças produtivas e das forças sociais (FALEIROS, 2009). E o poder do Estado fica mais evidente no capitalismo, já que o interesse estatal é para a manutenção da acumulação do capital (PAULO NETTO, 1992).

A argumentação de Paulo Netto (1992) nos dá indicativos de que as políticas sociais são antecipações estratégicas, quase sempre, atravessadas por contradições, conflitos e confrontos. Faleiros (2009), por exemplo, ressalta que as contradições são resultantes da luta de classes e, contraditoriamente, reproduzem as divisões de classes. Na visão de Faleiros (2009), e também de Offe (1984), o Estado capitalista atua como regulador das relações sociais a serviço da manutenção dos imperativos do capital, porque em sua intervenção aparentemente não mercantil, favorece a economia do mercado.

A estratégia do Estado na implantação de políticas sociais não depende somente das forças produtivas e do mercado, mas igualmente, do clima social e da relação das forças políticas (FALEIROS, 2009). Para Oliveira; Duarte (2005), tais políticas intervêm, em alta medida, nas lacunas advindas dos desequilíbrios na distribuição em favor da acumulação do capital, em seu conjunto, muito mais que a satisfação de necessidades básicas e promoção de igualdade.

A educação, como uma das mais importantes e elementares políticas sociais, de responsabilidade do Estado, estabelece-se em um processo de tomada de decisões que derivam nas normatizações do país, conhecidas como política educacional. Conforme argumentos de Oliveira; Duarte (2005); Silva (2016), ao mesmo tempo que a educação se afirma como uma política social de caráter universal, ela tem sido orientada também pela lógica da focalização, cujo princípio está em financiar os municípios com recursos adicionais, conforme a capacidade de realizar reformas administrativas de caráter gerencial.

As políticas de formação de professores no Brasil, por exemplo, tendem a colocar em pauta condicionantes para o desenvolvimento da sociedade e da economia, pesando a crítica em relação à perspectiva produtivista dessa formação. Sobre esta questão, Frigotto (1996) defende que a qualificação da formação de professores deve considerar outros condicionantes, para além das relações econômicas. Por esta razão, entender as políticas de formação de professores sugere compreender a política neoliberal, a qual privilegia o individual e a competitividade. Nesta direção estão as considerações de Freitas (1992), quando argumenta que as novas contradições geradas no interior da produção capitalista estão reacendendo o velho dilema entre educar e explorar.

A década de 1990 inaugurou novo direcionamento da educação brasileira, com a promulgação da LDB n. 9.394/96 e, sobre o dispositivo da formação de professores, o Art. 61, em seu parágrafo único, descreve os fundamentos dessa formação: I - a associação entre teorias e práticas, inclusive mediante a capacitação em serviço; II - aproveitamento da formação e experiências anteriores em instituições de ensino e outras atividades. Ressaltamos que as políticas de formação do professor foram delineadas e orientadas, principalmente a partir da década de 1990, por documentos e organismos internacionais, dentre os quais podemos citar os originados da Conferência Mundial da Educação de Jontiem (1990) e da Conferência de Dakar (2000) e indicações expressas pelo Banco Mundial, a UNESCO, a OCDE e a CEPAL. 
O Plano Decenal de Educação foi elaborado em 1993 pelo Ministério da Educação (MEC) em sintonia com as orientações contidas no documento da Conferência Mundial de Educação para Todos em Jomtien em 1990, destinado a cumprir um conjunto de diretrizes políticas voltadas para a recuperação da educação básica no país. Para tal, foram estabelecidas diretrizes para a formação inicial do professor, embora a crítica versa sobre o modelo de educação em posição de centralidade para a incorporação da sociedade no processo de produção (ARAÚJO, 2008).

O Brasil lançou em 2001, o Plano Nacional de Educação (2001-2010), pela via da Lei n. $10.172 / 2001$, no qual a formação de professores foi considerada como uma de suas principais dimensões. O Estado reconhecia, por meio do documento, a necessidade de formação de professores como um dos principais desafios. Lembramos que as políticas educacionais não têm ficado imunes à lógica do desenvolvimento econômico, e que a formação de professores também tem acontecido em perspectiva mercadológica, por vezes, enaltecendo modelos que se associam à perspectiva do desenvolvimentismo, na qual o professor é visto como responsável pelo preparo de alunos para o mercado de trabalho (MOTTA, 2009). Nesta direção, Kuenzer (1999) classifica este modelo como, fundamentalmente marcado pela precarização da formação, com implicações para o trabalho docente, ao centrar o processo na pedagogia das competências, cujos atributos são utilitaristas, à medida que caracterizam o trabalho do professor como forma de administrar as práticas pedagógicas, atribuindoIhe o lugar de profissional tarefeiro.

Em 2007, o Brasil apresentou o Plano de Metas Compromisso Todos pela Educação, via Decreto n. 6.094/2007, cujo objetivo era melhorar a educação do país, conforme está dito no Art. 10: "O Plano de Metas Compromisso Todos pela Educação é a conjugação dos esforços da União, Estados, Distrito Federal e Municípios, atuando em regime de colaboração, das famílias e da comunidade, em proveito da melhoria da qualidade da educação básica". Elaborado para abrigar ações já existentes e também novas ações gestadas no âmbito do Ministério da Educação, é considerado um Programa guarda-chuva, sendo anunciado como o Plano de Ações Articuladas (PAR) da educação (SCHNEIDER; NARDI; DURLI, 2012).

O Plano Nacional de Educação (2014-2024), por seu turno, trata do tema da valorização profissional e formação docente nas metas 15, 16, 17 e 18. A meta 15 está diretamente ligada a um dos projetos mais importantes do Governo Federal: o Plano Nacional de Formação dos Professores da Educação Básica (Parfor); a meta 16 indica a necessidade de termos mais professores pós-graduados em atividade; a meta 17 traz como ponto central a melhoria da qualidade da educação, incluindo a melhoria da qualidade dos professores; a meta 18 visa assegurar, no prazo de 2 (dois) anos, a existência de planos de carreira para os(as) profissionais da educação básica e superior pública de todos os sistemas de ensino (PNE, 2014-2024).

As políticas de formação de professores são diversas e uma tarefa em processo e, por esta razão, Kuenzer (1999) explica que não existe um modelo único de formação de professores, pois os modelos de formação têm como propósito, quase sempre, de responder às demandas que estão sendo apontadas pelo contexto das forças produtivas em desenvolvimento, em determinado momento. No espectro desta discussão, Garcia (1999) ressalta que é necessário compreender a formação de professores como um continuum, como um processo que tem que manter alguns princípios éticos, 
didáticos e pedagógicos comuns, independentemente do nível de formação em causa. Scheibe (2010, p. 987, grifo da autora), em seus argumentos, reconhece que é na formação docente que encontramos o foco central das políticas ocorridas no âmbito da educação brasileira desde a década de 1990. Em decorrência, "o professor, tido como agente de mudança, emerge, pois, cada vez mais como 0 responsáve/pela realização do ideário do século XXI".

Pensando nas políticas educacionais para a formação de professores, implantadas no Brasil, principalmente, a partir dessa década, ações pontuais voltadas para maior eficiência e eficácia, do ponto de vista dos resultados, da gestão escolar e da aplicação dos recursos parecem não ter dado conta de alcançar a qualidade que a escola pública precisa. Em pesquisa realizada por Schneider e Nardi (2015), os dados evidenciam o desenvolvimento de programas e ações que reforçam determinada visão de qualidade, nem sempre é coerente com as perspectivas educacionais proclamadas. As políticas parecem negligenciar, na maioria das vezes, a tensão entre o binômio quantidade-qualidade. Entendemos, portanto, que um dos caminhos para superar este desafio está em ampliar a efetiva participação dos sujeitos envolvidos no campo educacional nas esferas das decisões, das demandas prioritárias, do planejamento, da execução e da avaliação das políticas educacionais.

\section{POLÍTICAS DE FORMAÇÃO DE PROFESSORES: INSTITUCIONALIZAÇÃO NOS SISTEMAS MUNICIPAIS DE ENSINO NO ESTADO DO PIAUÍ}

O estado do Piauí está dividido em quatro mesorregiões geográficas: Norte, Centro-Norte, Sudeste e Sudoeste. Tomamos como referência, nesta pesquisa, os sistemas municipais de ensino no estado do Piauí, que, de acordo com informações do Conselho Estadual de Educação do Piauí, são 90 municípios², ou seja, $40 \%$ dos 224 municípios piauienses.

Tabela 1 - Frequência dos municípios piauienses com e sem sistema próprio de ensino por mesorregião

\begin{tabular}{|c|c|c|c|c|c|c|c|c|}
\hline \multirow{5}{*}{ 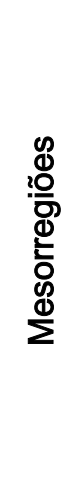 } & \multicolumn{2}{|c|}{$\begin{array}{l}\text { Norte Piauiense } \\
\text { (32 municípios) }\end{array}$} & \multicolumn{2}{|c|}{$\begin{array}{c}\text { Centro Norte } \\
\text { Piauiense } \\
\text { (64 municípios) }\end{array}$} & \multicolumn{2}{|c|}{$\begin{array}{l}\text { Sudeste Piauiense } \\
\text { (66 municípios) }\end{array}$} & \multicolumn{2}{|c|}{$\begin{array}{l}\text { Sudoeste Piauiense } \\
\text { (62 municípios) }\end{array}$} \\
\hline & Com & Sem & Com & Sem & Com & Sem & Com & Sem SME \\
\hline & SME & SME & SME & SME & SME & SME & SME & $(41 \mathrm{M})$ \\
\hline & $(10 \mathrm{M})$ & $(22 \mathrm{M})$ & $(34 \mathrm{M})$ & $(30 \mathrm{M})$ & (25 M) & $(41 \mathrm{M})$ & $(21 \mathrm{M})$ & \\
\hline & $31,25 \%$ & $68.75 \%$ & $53,1 \%$ & $46.9 \%$ & $37,9 \%$ & $62.1 \%$ & $33,9 \%$ & $66.1 \%$ \\
\hline
\end{tabular}

Fonte: Legislação municipal. Cômputo até o mês de dezembro de 2016.

\footnotetext{
${ }^{2}$ Cômputo em dezembro de 2016. Data limite de cômputo acordada no âmbito da Rede Mapa.
} 
A Tabela 1 mostra a situação em relação à institucionalização dos sistemas municipais de ensino no Piauí como uma tarefa inconclusa, sendo que a mesorregião Centro Norte é única que passa de $50 \%$ dos municípios com sistema próprio de ensino.

O Mapa 1 é um demonstrativo dos municípios com e sem sistemas próprios de ensino no estado do Piauí.

Mapa 1 - Situação da existência de sistemas municipais de ensino no Estado do Piauí - 2016.

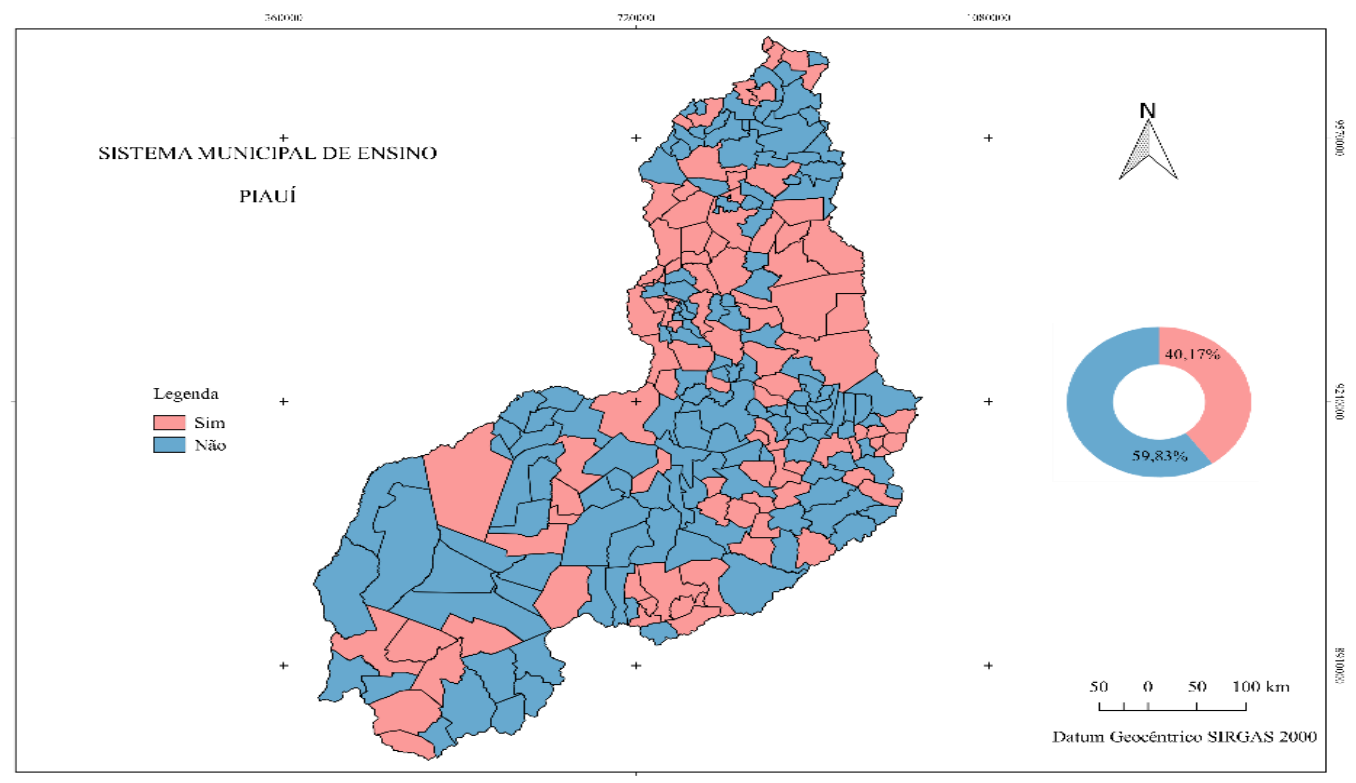

Fonte: Legislação municipal. Organização da autora. Cômputo até o mês de dezembro de 2016

O processo de institucionalização dos sistemas municipais de ensino no estado do Piauí segue as orientações da Lei Estadual n. 5.101, de 23 de novembro de 1999, que, por seu turno, adota as determinações da LDB de 1996 a respeito da organização dos sistemas de ensino e da constituição dos órgãos executivos (Secretaria Municipal de Educação) e normativo (Conselho Estadual de Educação) do sistema (Art. $8^{\circ}$ ).

O Parecer CEE/PI n. 054/2004 orienta os municípios do Piauí sobre a organização de seus Sistemas de Ensino: elaborar o Projeto de Lei do Sistema Municipal de Ensino contemplando a Secretaria Municipal de Educação (administrativo) e o Conselho Municipal de Educação (normativo); elaborar e implementar o Plano Municipal de Educação; encaminhar ao órgão legislativo municipal o Projeto de Lei de criação do SME, bem como a Lei de criação do CME para aprovação; comunicar sobre a institucionalização do SME ao Conselho Estadual de Educação do Piauí (CEE/PI), por intermédio de processo, cabendo a este comunicar, oficialmente, a decisão do município à Secretaria de Estado de Educação e Cultura do Piauí (Seduc/PI).

A legislação dos sistemas municipais de ensino no Piauí é elaborada mediante orientações do CEE-PI, o qual relaciona como um dos princípios desse processo a garantia da valorização do magistério, como meio necessário à busca da qualidade do ensino (PIAUÍ, 2004). Sobre esta questão, 
fizemos um levantamento das Leis de criação dos Sistemas Municipais de Ensino no âmbito de estado e identificamos quais tratam a respeito da valorização e da formação do profissional da educação, conforme podemos analisar no Gráfico 1.

Gráfico 1 - Legislação dos sistemas municipais de ensino no Estado do Piauí com e sem dispositivo sobre formação de professores

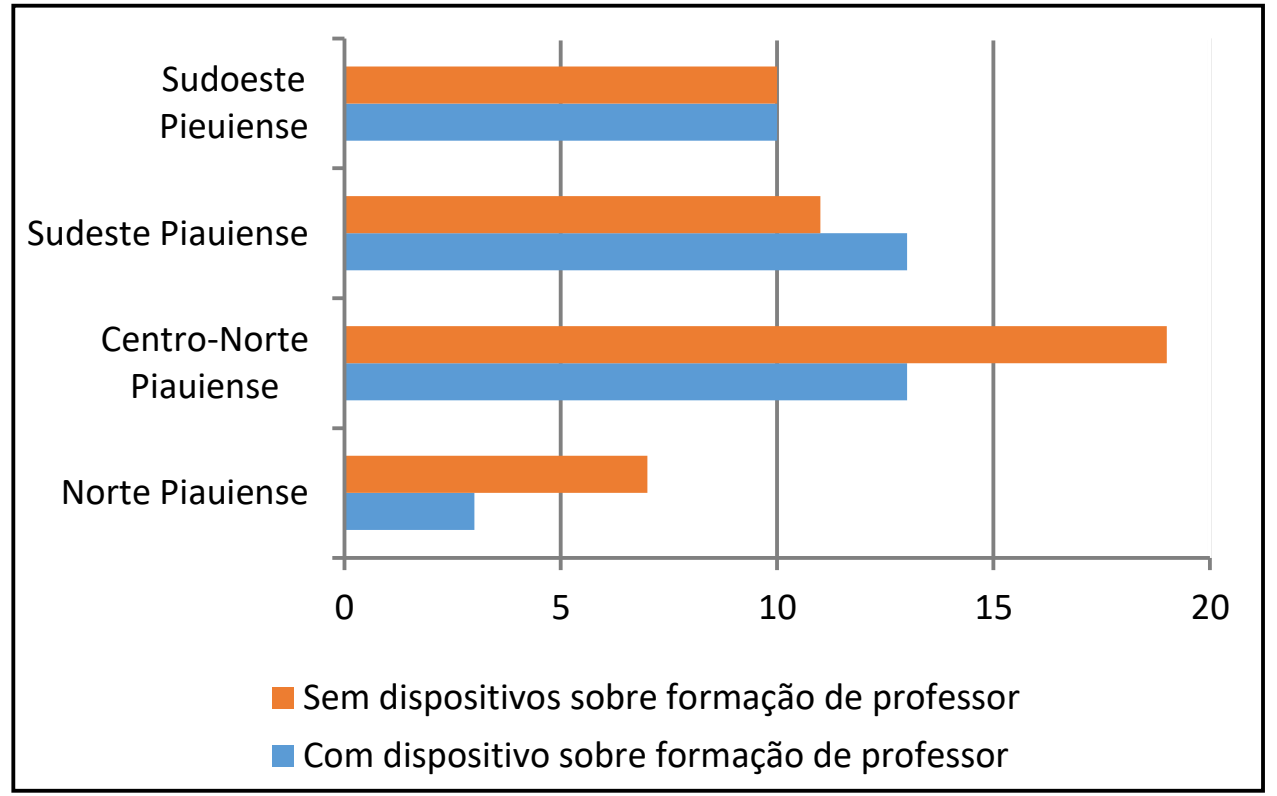

Fonte: Legislação Municipal. Cômputo até o mês de dezembro de 2016.

O Gráfico 1 nos mostra que em duas mesorregiões (Norte e Centro Norte), o número de leis dos sistemas municipais sem dispositivo sobre formação de professores supera o número de leis que trazem este assunto em seu texto. A mesorregião Sudoeste não apresenta diferenças quanto a esta questão e a mesorregião Sudeste, diferentemente das demais, a maior parte das leis dos sistemas municipais trata sobre a formação de professores.

Os dados nos revelam que há pouca preocupação dos municípios piauienses quanto à formação de profissionais da educação nos textos legais de criação dos sistemas municipais de ensino. Tomamos como base alguns condicionantes: o número baixo de municípios com sistema institucionalizado, cerca de $40 \%$ do total (90 de 224 municípios); do total de municípios autônomos (90), apenas 43,33\% (39 municípios) trazem no texto da lei de criação dos sistemas, os dispositivos sobre formação de professores. Isso se explica, possivelmente, pelo fato de os municípios esperarem por políticas públicas de formação de professor, implementadas e financiadas em regime de colaboração, pelo governo federal e/ou estadual.

Identificada a recorrência do tema "formação de professores" no conjunto das leis municipais, passamos, então, à análise do conteúdo dos textos. Tal conteúdo está sintetizado na Tabela 2: orientações para a formação de professores e a frequência com que aparece nas leis por mesorregião. 
Tabela 2 - Dispositivos sobre formação de professores na legislação dos sistemas municipais de ensino no Estado do Piauí

\begin{tabular}{|c|c|c|c|c|c|}
\hline \multirow[b]{2}{*}{ Orientações para a formação de professores } & \multicolumn{5}{|c|}{ Frequência } \\
\hline & $\begin{array}{l}\text { Norte } \\
\text { (3 leis) }\end{array}$ & $\begin{array}{l}\text { Centro- } \\
\text { Norte } \\
\text { (13 leis) }\end{array}$ & $\begin{array}{l}\text { Sudest } \\
\text { e } \\
\text { (13 } \\
\text { leis) }\end{array}$ & $\begin{array}{l}\text { Sudoest } \\
\qquad \begin{array}{l}\text { e } \\
\text { (10 leis) }\end{array}\end{array}$ & $\begin{array}{l}\text { Total } \\
\text { (39 leis) }\end{array}$ \\
\hline $\begin{array}{l}\text { 1. Programas de atualização e } \\
\text { aperfeiçoamento }\end{array}$ & 2 & 6 & 7 & 4 & $\begin{array}{l}19(48,7 \\
\%)\end{array}$ \\
\hline $\begin{array}{l}\text { 2. Valorização assegurada no Plano de } \\
\text { Carreira }\end{array}$ & 1 & 1 & - & 3 & $\begin{array}{l}5 \\
(12,8 \%)\end{array}$ \\
\hline $\begin{array}{l}\text { 3. Formação contínua e sistemática, através } \\
\text { de cursos específicos }\end{array}$ & - & 1 & 5 & 2 & $\begin{array}{l}8 \\
(20,5 \%)\end{array}$ \\
\hline $\begin{array}{l}\text { 4. Aperfeiçoamento continuado, previsto no } \\
\text { Estatuto e Plano de Carreira, com } \\
\text { licenciamento }\end{array}$ & - & 5 & - & - & $\begin{array}{l}5 \\
(12,8 \%)\end{array}$ \\
\hline $\begin{array}{l}\text { 5. A SME desenvolverá programas de } \\
\text { formação continuada para profissionais da } \\
\text { educação municipal }\end{array}$ & - & - & 1 & - & $1(2,5 \%)$ \\
\hline $\begin{array}{l}\text { 6. Fundamentos: formação sólida, associação } \\
\text { teoria e prática, aperfeiçoamento da } \\
\text { formação }\end{array}$ & - & - & - & 1 & $1(2,5 \%)$ \\
\hline
\end{tabular}

Fonte: Legislação municipal. Cômputo até o mês de dezembro de 2016.

Os dados da Tabela 2, embora sem especificar como os municípios materializarão a formação dos profissionais da educação, nos apresentam indicativos de que se trata de formação continuada por intermédio de programas de atualização. Destacamos o que determinam as Leis analisadas, porém, não fazemos referência a quais municípios descrevem seus dispositivos de formação de professores e valorização profissional, apenas o quantitativo em relação às categorias identificadas. Não podemos afirmar se há uma correspondência direta entre o que está determinado na Lei e a realidade dos sistemas municipais de ensino, visto que a finalidade do estudo está em analisar as bases normativas sobre formação de professores na legislação municipal.

O conjunto da legislação analisado nos permite identificar categorias, as quais podemos agrupálas nestas dimensões: atualização e aperfeiçoamento; valorização e formação sólida; associação entre a teoria e a prática. Os textos analisados não trazem esclarecimentos quanto aos modelos das propostas de formação continuada e atualização profissional dos professores, porém, cabe-nos fazer algumas reflexões acerca das particularidades relacionadas aos programas de formação. Para fazermos tais reflexões, levamos em consideração alguns condicionantes das políticas educacionais de 
formação de professores, em especial, no pós-LDB/96: o Estado capitalista, a reforma do Estado dos anos 90 , organismos internacionais, precarização da formação.

No âmbito do Estado capitalista, as políticas sociais e educacionais são delineadas para a promoção do desenvolvimento das forças produtivas, logo, são modelos elaborados para promover o fortalecimento do campo econômico. Neste caso, o Estado atua como regulador das forças sociais a serviço dos imperativos do mercado (FALEIROS, 2009; OFFE, 1984), promovendo políticas orientadas pela lógica da focalização, de caráter gerencial (DUARTE; OLIVEIRA, 2005). Assim, as políticas de formação de professores tendem a se fundamentar por condicionantes para o desenvolvimento da sociedade e da economia (FRIGOTTO, 1996).

Os anos de 1990 marcaram a reforma do Estado brasileiro, delineando as políticas sociais e educacionais pela lógica da produtividade e da eficiência, logo, o ideário neoliberal. Em análise feita por Dourado (2002), as políticas públicas, do ponto de vista da reforma, preconizaram mudanças na forma de organização da sociedade propondo uma gestão fundamentada na gerência, como forma de organizar e modernizar a sociedade. Nesta arena, os reflexos do ideário da reforma passaram a ser sentidos pelas políticas educacionais, estas passando, de alguma forma, a representar a visão de mercado, reforçando a concorrência e a produtividade.

Entram em cena, com maior visibilidade, os organismos multilaterais munidos do ideário neoliberal, como o Banco Mundial, o Banco Interamericano de Desenvolvimento, a Unesco, o OCDE, com orientações para a descentralização, a produtividade, a eficiência e a eficácia, presentes nas políticas educacionais e, em consequência, nos programas de formação de professores. Pacheco; Moraes; Evangelista (2001) nos chamam à atenção, visto que a proposta da formação de professores tem sido articulada com medidas desses organismos, vendo no professor um protagonista da modernização e da produtividade, o que nos permite inferir que a formação tem adotado modelos para atender uma perspectiva mercadológica (MOTTA, 2009), o que implica dizer que são modelos marcados, em sua maioria, pela precarização (KUENZER, 1999).

Uma questão que nos parece central neste debate diz respeito à priorização dos interesses econômicos no cerne das políticas de formação de professores, o que pode levar à precarização da formação, que estamos referindo. A formação, na perspectiva capitalista, é elaborada pelo viés de uma gerência científica, propondo uma formação para atender às exigências do mercado e criticada, por vezes, por apresentar uma estrutura fragmentada e aligeirada, ou seja, cursos de aperfeiçoamento e de curta duração, em períodos de férias ou finais de semana, uma espécie de treinamento e aperfeiçoamento, como é possível serem identificados no conjunto da legislação analisada.

Citamos exemplos de políticas nacionais de formação de professores, especialmente no pósLDB/96, implementadas no estado do Piauí tanto na rede estadual quanto nas redes municipais de ensino público, independente do município ter ou não sistema de ensino institucionalizado,

1. Convênio celebrado entre a Universidade Estadual do Piauí/Secretaria Estadual de Educação/Secretaria Municipal de Educação: cursos de licenciaturas para formar os professores dos sistemas estaduais e municipais do Piauí, os quais funcionaram, 
especialmente, entre os anos de 1997 a 2007, sob a denominação de Cursos de Regime Especial.

2. PROFORMAÇÃO: Destinado aos professores que, sem a formação específica, encontram-se no exercício do magistério nas séries iniciais do Ensino Fundamental, Educação Infantil ou na modalidade EJA das redes públicas de ensino do país. No Piauí este Programa foi implantado no ano 2000 e funcionou até o ano 2004.

3. PARFOR: Programa instituído para atender o disposto no artigo 11 do Decreto n. 6.755/2009 e implantado em regime de colaboração entre a Capes, os estados, os municípios, o Distrito Federal e as Instituições de Ensino Superior. Funciona em três modalidades: licenciatura, segunda licenciatura, formação pedagógica. No Piauí, a UESPI, a UFPI e o IPFI implementaram a formação de professores com a oferta de cursos de Educação Superior pela via do Parfor desde 2010.

4. Sistema UAB: Criada pelo Ministério da Educação, em 2005, com o objetivo de expandir a oferta de cursos superiores em instituições públicas (graduação e pós-graduação). No estado do Piauí, a Universidade Federal do Piauí (UFPI) e a Universidade Estadual do Piauí (UESPI), por meio da Universidade Aberta do Piauí, têm contribuído na oferta de cursos de formação de professores (licenciaturas), tanto de graduação quanto de pós-graduação, financiados pelo governo federal por intermédio da Capes.

5. QUALIESCOLA: Programa desenvolvido pelo Instituto Qualidade na Escola, uma organização não governamental, que consiste na capacitação presencial e a distância de gestores e professores de escolas públicas de ensino fundamental, com foco na melhoria da qualidade da aprendizagem. No Piauí, o Programa teve início no ano de 2006, atendendo inicialmente quatro municípios: Teresina, Campo Maior, José de Freitas e Parnaíba, qualificando professores vinculados à Seduc-PI.

6. PNAIC: Programa voltado à formação de professores, sem deixar de ter a avaliação como horizonte para atingir melhores índices nas avaliações nacionais (AMARAL, 2015). No Piauí, todos os 224 municípios aderiram ao PNAIC desde 2012, com início do programa em 2013. Com a adesão de todo o Estado, o Piauí reafirma e amplia o compromisso estabelecido pelo Decreto n. 6.094/2007, de alfabetizar as crianças de escolas públicas rurais e urbanas até, no máximo, os oito anos de idade.

7. PIBID: Criado pelo MEC-CAPES-FNDE, com a finalidade de valorizar o magistério e apoiar estudantes de licenciatura, das instituições públicas e comunitárias, sem fins lucrativos, de educação superior. No Piauí, a UESPI, a UFPI e o IFPI aderiram ao PIBID, como uma recomendação de própria LDB de 1996.

Destacamos alguns dos programas, pelo menos, os mais visíveis, de alcance em todo o Piauí, materializados nos municípios. Os programas de formação de professores e valorização do profissional da educação implantados no estado compreendem o modelo do pacto federativo, de colaboração entre a União, o Estado e os Municípios, observando as normas nacionais legais e as peculiaridades locais. 
Identificamos, porém, que tais políticas vêm sendo implantadas com maior intensidade a partir da década de 1990, porque, além da necessidade de formação do professor, uma realidade em todo território nacional, destacamos também ser esta formação uma exigência legal, conforme determina a LDB n. 9394/96 no Art. 62. O Plano Nacional de Educação (2001-2011) reforçou a necessidade da implantação de políticas públicas de formação inicial e continuada dos profissionais da educação, como uma condição e um meio para o avanço da sociedade e para o desenvolvimento do país (10.2 Diretrizes). O atual Plano Nacional de Educação (2014-2024), na meta 15 afirma: "garantir em regime de colaboração entre a União, os estados, o Distrito Federal e os municípios [...], política nacional de formação de profissionais da educação [...]". Seguindo as orientações da legislação a nível nacional, municípios piauienses, independente de terem ou não sistema de ensino institucionalizado, implantaram, em regime de colaboração, políticas de formação inicial e continuada de professores, com a participação das instituições UESPI, UFPI, IFPI e UAB/PI.

Pesa a crítica sobre essas políticas, por serem programas de formação aligeirados, para fins de cumprimento legal, assim como, de orientações internacionais advindas da UNESCO, Banco Mundial, OCDE. São políticas que reforçam a centralidade da formação como um recurso de modernização da sociedade e dos sistemas de ensino (PACHECO; MORAES; EVANGELISTA, 2001), e, como não é demais afirmar, reforçam a precarização se não se constituir de um modelo que assegure a dignidade do professor e a garantia de condições adequadas de trabalho (KUENZER, 2009).

Para exemplificar a precarização, citamos o parecer do Conselho Estadual de Educação do Piauí (Processo CEE/PI n. 218/2006), no qual está dito que os cursos de formação de professores em Regime Especial ofertados pela Universidade Estadual do Piauí não proporcionavam uma discussão mais rigorosa, além de serem estimulados por interesses imediatistas dos municípios, o que nos leva a entender que eram cursos sustentados, basicamente, em um modelo pragmático, um mecanismo para atender à demanda emergente por formação de trabalhadores em educação, com custos reduzidos.

Quais as características dos alunos desses cursos? Destacamos o perfil dos alunos das licenciaturas do Regime Especial, o Proformação e o Parfor. Começamos pelos alunos do Proformação: os alunos, ao ingressarem no curso, deixavam de ser professores leigos e passavam a ser cursistas; em sua maioria, eram alunos com o ensino fundamental incompleto que atuavam em escolas, preponderantemente localizadas na zona rural; o curso dava a eles o certificado de Ensino Médio. Os cursos do Regime Especial e o Parfor apresentam algumas semelhanças, principalmente, em termos de organização curricular; os alunos são professores em exercício; os cursos são ofertados para quem não tem licenciatura, mas também, para quem tem licenciatura, mas que está ministrando aulas fora de sua área da formação; são ministrados nos meses de julho, janeiro e fevereiro.

Os programas de formação continuada (Qualiescola e Pnaic) e iniciação à docência (Pibid) são implementados nos municípios em regime de colaboração. São programas de formação firmados no modelo pedagógico-didático, visando, fundamentalmente, o desenvolvimento de competências. Acreditamos, entretanto, em um modelo de formação, seja inicial ou continuada, o qual vise em seu currículo, conhecimentos dos diferentes modos como a educação se manifesta enquanto prática social, bem como contribua para a direção de sentido que se quer dar para o humano (PIMENTA, 1995), como uma proposta para além do ideário imperativo do mercado e a lógica do capital. 
Em síntese, as transformações econômicas, ideológicas e políticas têm impactado a sociedade e, em consequência, o setor da educação e as políticas educacionais, especificamente, as de formação de professores, as quais têm sido elaboradas levando em conta as influências da lógica capitalista. Neste contexto, os sistemas de ensino elaboram as políticas de formação de professores, seguindo as orientações de ordem nacional e, em alguma medida, mediadas por delineamentos de organismos internacionais, ou seja, modelos de formação para atender, em primeira instância, a lógica imediatista do mercado: programas de atualização, aperfeiçoamento, cursos de curta duração e de formação de competências.

\section{CONCLUSÕES}

O estudo a respeito das políticas de formação de professores no âmbito das leis de criação dos sistemas municipais de ensino no estado do Piauí nos permite tecer algumas considerações. No campo teórico, reconhecemos que as políticas sociais no Brasil são reflexos dos imperativos do sistema capitalista; são políticas atravessadas por contradições e lutas impostas pela ordem do capital; mas, também, formam um conjunto de ações do Estado no atendimento imediato das necessidades da classe trabalhadora. As políticas educacionais e de formação de professores, no Brasil, ganharam mais força a partir dos anos 1990, com as chamadas ações compensatórias; tendem a colocar em pauta o contexto de desenvolvimento da sociedade e da economia; foram implementadas sob orientações de organismos internacionais; do ponto de vista legal, foram implementadas a partir de documentos nacionais, como a Constituição Federal (1988), a LDB (1996), os PNEs (2001 e 2014).

Do ponto de vista empírico, constatamos que as diretrizes para a formação de professores no Piauí, conforme o conjunto da legislação municipal, tendem a levar em conta, principalmente, as necessidades imediatas dos municípios; também nos levam a admitir que os cursos não vão muito além de atualização e aperfeiçoamento do professor e a formação de competências, permitindo um certo empobrecimento cultural e profissional, causado pelo descompasso entre os objetivos proclamados pelas políticas e a materialização da formação. Os exemplos pontuais citados no texto destacam a presença do pacto federativo e o regime de colaboração entre os entes federados, assim como a participação das instituições de ensino superior no processo de formação de professores (UESPI, UFPI, IFPI, UAB/PI).

Consideramos, portanto, que este estudo fica inconcluso, merecendo ser aprofundado em aspectos, para além da análise da legislação de institucionalização dos sistemas de ensino, mas, sobretudo, merece um aprofundamento sobre o processo de materialização das políticas aqui mencionadas. Cabe uma análise das políticas de formação inicial e continuada de professores implementadas nos municípios piauienses, considerando: as propostas curriculares dos programas implementados; o perfil dos alunos, dos professores e das instituições de ensino superior; os tipos de materiais didático-pedagógico utilizados na formação; mecanismos de avaliação das políticas; impactos das políticas materializadas do ponto de vista educacional, social e econômico. 


\section{REFERÊNCIAS}

1. ALARCÃO, Isabel. Formação continuada como instrumento de profissionalização docente. In: VEIGA, Ilma Passos Alencastro (Org.). Caminhos da profissionalização do magistério. Campinas: Papirus, 2003, p. 99-122.

2. AMARAL, Arlene de Paula Lopes. Formação continuada de professores: reflexões sobre a participação no Pacto Nacional pela Alfabetização na Idade Certa. Cad. Cedes, Campinas, v. 35, n. 95, p. 127-133, jan./abr. 2015.

3. ARAÚJO, Nataniel da Vera-Cruz Gonçalves. O Normal Superior telepresencial e a trilogia: política educacional, formação de professoras (es) e educação a distância. 2008. Dissertação (Mestrado em Educação). Universidade Federal do Maranhão, São Luís, 2008.

4. BARDIN, Laurence. Análise de Conteúdo. Lisboa-Portugal: Edições 70, LDA, 2010.

5. BRASIL. Constituição Federal. Brasília-DF: Senado Federal, 1998.

6

Decreto n. 6.094, de 24 de abril de 2007. Dispõe sobre a implementação do Plano de Metas Compromisso Todos pela Educação, pela União Federal, em regime de colaboração com Municípios, Distrito Federal e Estados, e a participação das famílias e da comunidade, mediante programas e ações de assistência técnica e financeira, visando a mobilização social pela melhoria da qualidade da educação básica. Disponível em: <www.dominiopublico.gov.br>. Acesso em: 01 jun. 2017.

Decreto n. 6.755, de 29 de janeiro de 2009. Institui a Política Nacional de Formação de Profissionais do Magistério da Educação Básica, disciplina a atuação da Coordenação de Aperfeiçoamento de Pessoal de Nível Superior - CAPES no fomento a programas de formação inicial e continuada, e dá outras providências. Brasília, DF: MEC, 2009.

Decreto n. 8.752, de 9 de maio de 2016. Dispõe sobre a Política Nacional de Formação dos Profissionais da Educação Básica. Brasília, DF: Presidência da República/Casa Civil/Subchefia para Assuntos Jurídicos. Disponível em: <http://www.planalto.gov.br/ccivil_03/_Ato20152018/2016/Decreto/D8752.htm>. Acesso em: 29 maio 2017. providências. Disponível em: <http://portal.mec.gov.br/arquivos/pdf/L10172>. Acesso em: 06 jun. 2017. 

outras providências. Diário Oficial União, Poder Executivo, Brasília, DF, Edição Extra, n. 120-A, 26 jun. 2014. Seção 1, p. 1-8. 1996.

. Lei de Diretrizes e Bases da Educação Nacional n. 9394/96. Brasília, DF: Senado Federal, Brasília, ano 12, n. 54, p. 3-322, abr./jun. 1992.

17. FRIGOTTO, Gaudêncio. A formação e a profissionalização do educador: novos desafios. In: SILVA, Tomaz Tadeu e GENTILI, Pablo (Org.). Escola S.A. quem ganha e quem perde no mercado educacional no neoliberalismo. Brasília, DF: CNTE, 1996. p. 75-105. Portugal: Porto Editora, 1999. Sociedade, v. 31, n. 113, p. 1355-1379, 2010. HARGREAVES, Andy. Aprendendo a mudar: o ensino para além dos conteúdos e da padronização. Porto Alegre: Artmed, 2002.

21. IMBERNÓN, Francisco. Formação continuada de professores. Porto Alegre: Artmed, 2010.

22. KUENZER, Acácia Zeneida. As políticas de formação: $A$ constituição da identidade do professor sobrante. Educação e Sociedade, Campinas, v. 20, n. 68, p. 163-183, dez. 1999.

23. MOTTA, Vânia Cardoso. Ideologias do capital humano e do capital social: da integração à inserção e ao conformismo. Revista Trab. Educ. Saúde, v. 6, n. 3, p. 549-571, nov./fev. 2009. 
OLIVEIRA, Dalila Andrade; DUARTE, Adriana. Política educacional como política social: uma nova regulação da pobreza. Perspectiva, Florianópolis, v. 23, n. 2, p. 279-301, jul./dez. 2005.

26. PACHECO, José Augusto; MORAES, Maria Célia Marcondes de; EVANGELISTA, Olinda. Políticas educacionais nos anos 90: a formação de professores no Brasil e em Portugal. Educar, Curitiba, n.18, p. 185-199. 2001. Editora da UFPR.

27. PAULO NETTO, José. Capitalismo Monopolista e Serviço Social. São Paulo: Cortez, 1992.

28. PIAUÍ. Lei n. 5.101, de 23 de novembro de 1999. Dispõe sobre o sistema de ensino do Estado e dá outras providências. Disponivel em: <http://servleg.al.pi.gov.br:9080/ALEPI/sapl_documentos/norma_juridica/1812_texto_integral>. Acesso em: 10 mar. 2016.

Parecer CEE/PI n 054, de 03 de dezembro de 2004. Orienta os municípios do Piauí sobre a organização de seus Sistemas de Ensino e dá outras providências. Teresina: Conselho Estadual de Educação, 2004.

Processo CEE n. 218/2006, de 07 de março de 2006. Solicitação de reconhecimento de cursos de História, Regime Especial. Interessada: Universidade Estadual do Piauí. Disponível em: <www.ceepi.pro.br>. Acesso em: 29 maio 2017. <http://piauinoticias.com/site/educacao>. Acesso em: 03 jun. 2017.

32. PIMENTA, Selma Garrido. Formação de professores: identidades e saberes na docência. In: PIMENTA, Selma Garrido. (Org.). Saberes pedagógicos e atividade docente. São Paulo: Cortez, 1999. p. 15-34. O estágio na formação de professores: unidade entre teoria e prática. Cadernos de Pesquisa, São Paulo, n. 94, p. 58-73, 1995.

SAVIANI, Demerval. O Plano de Desenvolvimento da Educação: análise do projeto do MEC. Educ. Soc., Campinas, v. 28, n. 100, Especial, p. 1231-1255, out. 2007. Formação de professores: aspectos históricos e teóricos do problema no contexto brasileiro. Revista Brasileira de Educação, v.14, n. 40, jan/abr, p. 143-155, 2009. 
38. SILVA, Luiz Gustavo Alexandre. Programa de Apoio aos Dirigentes Municipais de Educação PRADIME: entre a intencionalidade formativa e a responsabilização educacional. In: FERREIRA, Suely. Políticas e gestão da educação nos municípios goianos: planejamento, financiamento e carreira docente. Goiânia: Gráfica UFG, 2016. p. 17-34.

39. SCHEIBE, Leda. Valorização e formação dos professores para a educação básica: questões desafiadoras para um Plano Nacional de Educação. Educ. Soc., Campinas, v. 31, n. 112, p. 9811000, jul./set. 2010.

40. SCHNEIDER, Marilda Pasqual; NARDI, Elton Luiz; DURLI, Zenilde. O PDE e as metas do PAR para a formação de professores da educação básica. Ensaio: aval. pol. públ. Educ., Rio de Janeiro, v. 20, n. 75, p. 303-324, abr./jun. 2012.

41. SCHNEIDER, Marilda Pasqual; NARDI, Elton Luiz. Políticas educacionais e regulação da qualidade da educação básica. In: SCHNEIDER, Marilda Pasqual; NARDI, Elton Luiz (Org.). Qualidade da educação no Ensino Fundamental: entre políticas e a (ex)tensão do tema na escola pública. ljuí: Ed. Unijuí, 2015. p. 27-46.

42. UNESCO. Declaração Mundial sobre Educação para Todos: satisfação das necessidades básicas de aprendizagem Jomtien, $1990 . \quad$ Disponível em: <unesdoc.unesco.org/images/0008/000862/086291por.pdf>. Acesso em: 10 jun. 2017. 28 de abril de 2000. Disponível em: <unesdoc.unesco.org/images/0012/001275/127509porb.pdf>. Acesso em: 10 jun. 2017.

\section{Raimunda Maria da Cunha Ribeiro}

Doutora pelo Programa de Pós-Graduação em Educação da Pontifícia Universidade Católica do Rio Grande do Sul em Porto Alegre-RS. Realizou estágio Pós-Doutoral no Programa de Pós-Graduação em Educação da Universidade do Oeste de Santa Catarina em Joaçaba (2016). Professora da Universidade Estadual do Piauí no curso de Pedagogia. 


\section{Com citar este documento:}

RIBEIRO, Raimunda Maria da Cunha. Políticas de formação de professores: o que determina a legislação de criação de sistemas municipais de ensino no Estado do Piauí. Reflexão e Ação, Santa Cruz do Sul, v. 28, n. 1, jan. 2020. ISSN 1982-9949. Disponível em: <https://online.unisc.br/seer/index.php/reflex/article/view/12324>. Acesso em: doi:https://doi.org/10.17058/rea.v28i1.12324. 